\title{
HOW ACCURATELY CAN UROLOGISTS PREDICT ELIGIBLE PATIENTS FOR IMMEDIATE POSTOPERATIVE INTRAVESICAL CHEMOTHERAPY IN BLADDER CANCER?
}

\author{
Hüseyin Alperen Yıldız ${ }^{1}$ Dogan Deger ${ }^{2}$, and Guven Aslan ${ }^{3}$ \\ ${ }^{1}$ Malazgirt State Hospital \\ ${ }^{2}$ Edirne Sultan Murat 1 State Hospital \\ ${ }^{3}$ Dokuz Eylül University
}

December 18, 2020

\begin{abstract}
Purpose: To assess the ability of urology residents and experienced urologists to accurately predict pathological features of bladder tumors based solely on cystoscopic appearance, and evaluate how accurately urologists can decide eligible patients for postoperative intravesical chemotherapy. Methods: 104 patients with bladder mass were included, 7 senior urologists and 4 residents joined the study. Before resection, both specialists and residents were asked to predict the stage, grade of the tumor, and presence of CIS. We obtained resident predictions for 104 patients and senior predictions for 72 of these patients. Based on these predictions, eligibility of the patients for single postoperative immediate chemotherapy were determined according to EAU NMIBC guidelines. After final pathology report, risk scores recalculated and compared with surgeons' predictions. Results: In correlation analysis, strong agreement with the pathological report could not be demonstrated with any of the stages, grades, and presence of CIS for both senior and resident urologists. Urology residents' predictions were slightly more accurate than the senior urologists'. According to senior urologists' predictions, 14/72 (19,4\%) of the patients, and according to residents' predictions, $19 / 104(18,2 \%)$ of the patients were found to be either overtreated or undertreated. Conclusions: Cystoscopic visual prediction is not sufficient to decide on immediate postoperative intravesical chemotherapy regardless of the experience, and we need more objective parameters to improve the appropriate patient selection. What's known: In patients with nonmuscle invasive bladder cancer (NMIBC), decision of immediate postoperative chemotherapy instillation is made by urologists according to clinical and "presumed" pathological parameters as definitive pathology is unkown. Therefore, the concordance of this presumption with the final pathology is important. What's new: In our study, we demonstrated that urologists' predictions on pathological features are not reliable to decide on immediate postoperative intravesical chemotherapy instillation and better criteria for patient selection are needed.
\end{abstract}

HOW ACCURATELY CAN UROLOGISTS PREDICT ELIGIBLE PATIENTS FOR IMMEDIATE POSTOPERATIVE INTRAVESICAL CHEMOTHERAPY IN BLADDER CANCER?

Hüseyin Alperen Yıldız a, ${ }^{*}$, Müslim Doğan Değer ${ }^{b}$, Güven Aslan ${ }^{c}$

${ }^{a}$ Department of Urology, Malazgirt State Hospital, Muş, Turkey

b Department of Urology, Edirne State Hospital, Edirne, Turkey

${ }^{c}$ Department of Urology, Dokuz Eylül University, School of Medicine, İzmir, Turkey

Short Title: CAN UROLOGISTS CHOOSE RIGHT PATIENTS FOR SI?

${ }^{*}$ Corresponding Author: Hüseyin Alperen Yıldız 
Malazgirt State Hospital, Department of Urology

Address: Saltukgazi Mahallesi, Hastane Cd., Malazgirt, Muş, Turkey, 49400

Tel: +902324443511

E-mail: h.alperenyildiz@gmail.com

Acknowledgments:

None

Disclosure Statement:

The authors have no conflicts of interest to declare.

Funding Sources:

The authors received no specific funding for this work.

\section{Hosted file}

text.pdf available at https://authorea.com/users/379749/articles/499553-how-accuratelycan-urologists-predict-eligible-patients-for-immediate-postoperative-intravesicalchemotherapy-in-bladder-cancer 